\title{
Plasmocitoma solitario a nivel de T4 y T5
}

\author{
Solitary plasmacytoma at T4 and T5 \\ Christian Gerardo Colín González, ${ }^{*}$ Esteban Reyes Velasco ${ }^{\ddagger}$
}

Paciente femenino de 39 años de edad con antecedentes familiares de cáncer de páncreas (padre) y cáncer de estómago (madre). Presenta dolor en la región torácica, debilidad e hipoestesia progresiva generalizada, que predomina en los miembros pélvicos, de un mes de evolución.

$\mathrm{Al}$ momento de la exploración física se encontraron las extremidades torácicas normales, pero alteraciones de la sensibilidad a nivel de T4; las extremidades pélvicas presentan paraparesia con calificación 3-4/5 de manera global bilateral; reflejos osteotendinosos incrementados y reflejo de Babinski bilateral. Con impresión diagnóstica de mielopatía torácica compresiva, se realizó una resonancia magnética de columna torácica (Figura 1) y se encontró una masa tumoral homogénea, isointensa, de localización intrarraquídea extramedular desde el borde superior de T4 hasta el borde inferior de T5.

Figura 1:

Imágenes de resonancia magnética. A) Ponderada en T2. B) Ponderada en T1, ambas en corte sagital, extra-medular localizada a nivel T4 y T5 (flechas), ventral de la médula espinal. C y D) En cortes axiales.
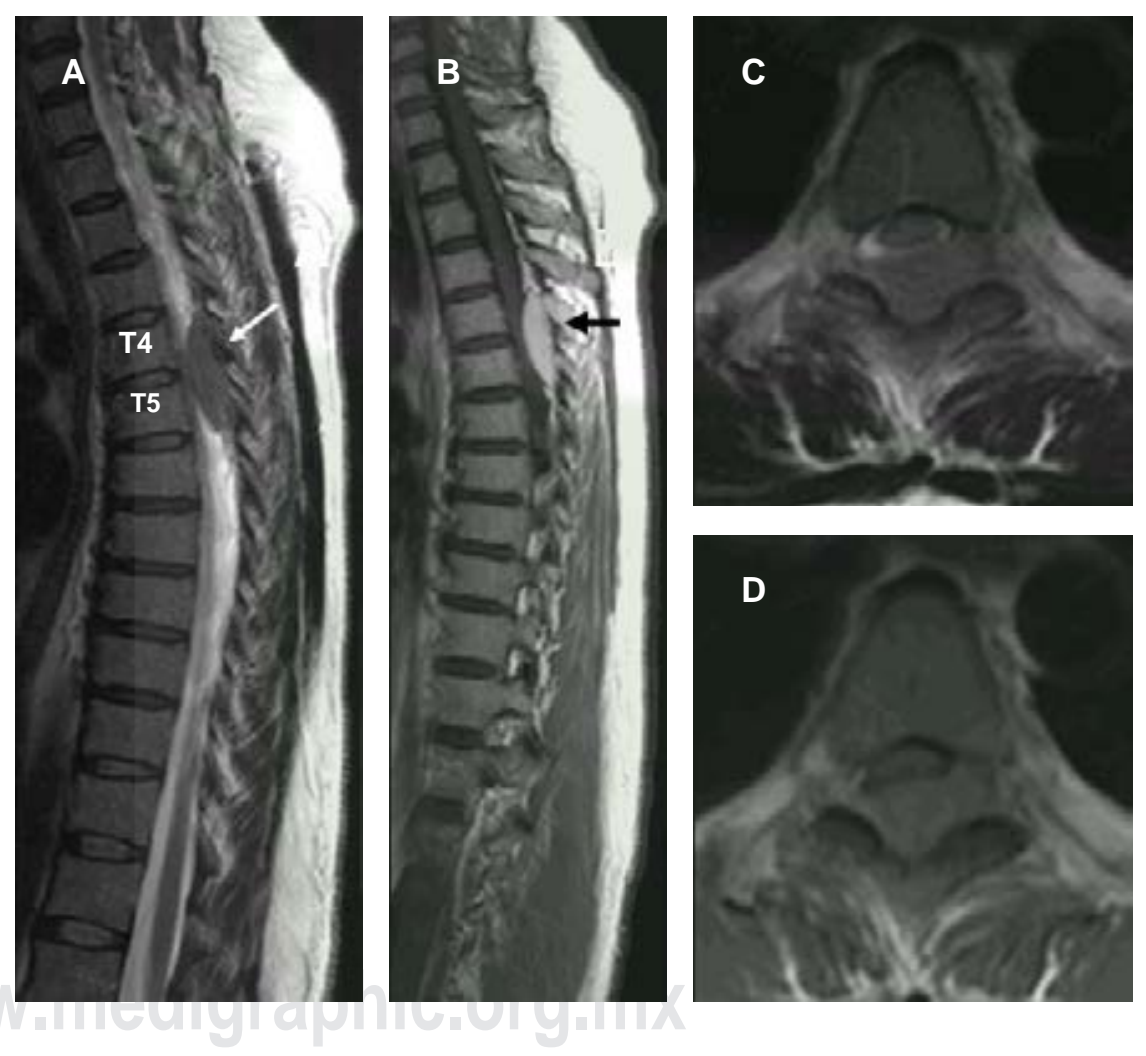

\footnotetext{
* Ortopedista y Cirugía de Columna.

* Neurocirujano.
}

Correspondencia:

Christian Gerardo Colín González

Correo electrónico: drchristiancolin@gmail.com

División de Cirugía del Hospital Ángeles León. León, Guanajuato México.

Aceptado: 09-09-2019.

www.medigraphic.com/actamedica 

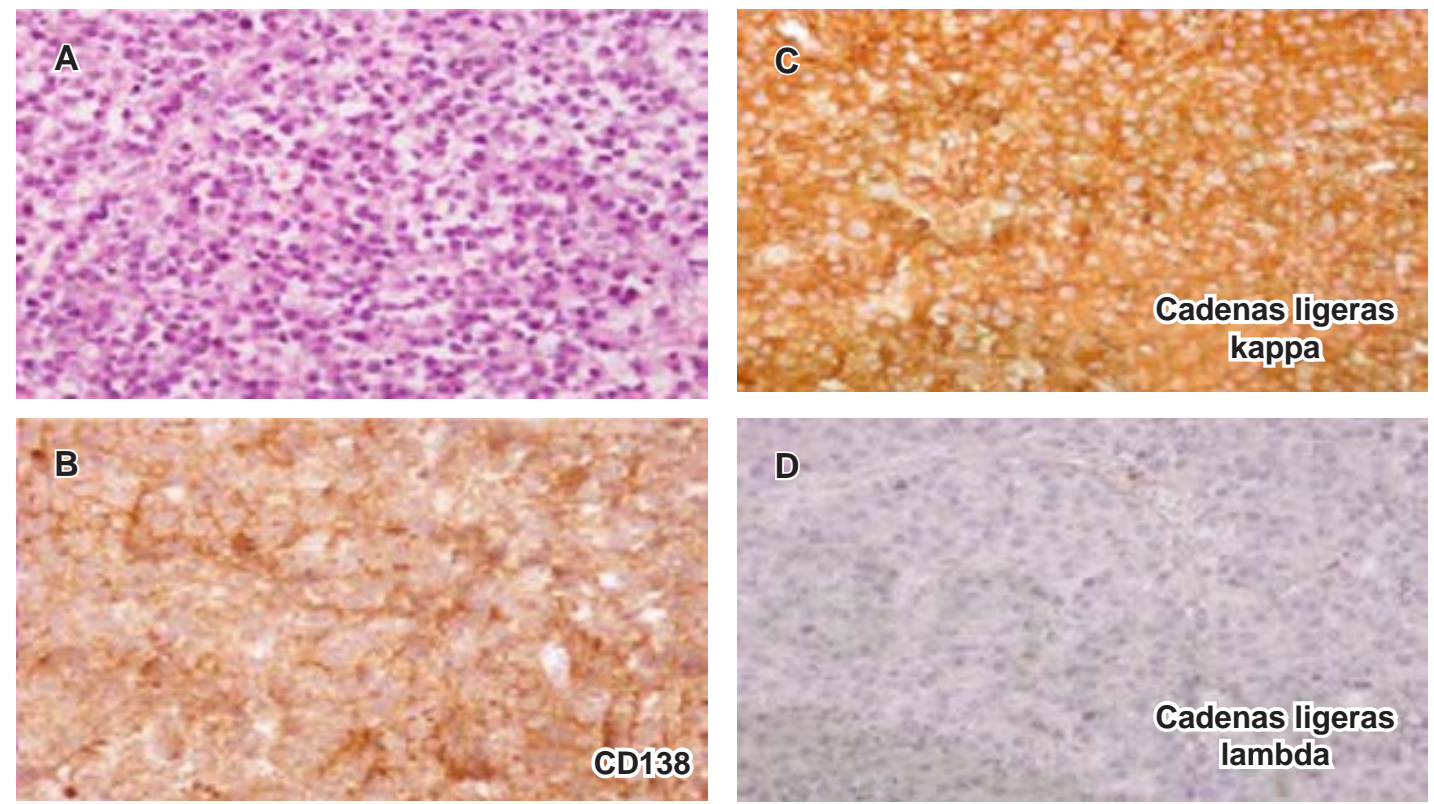

Figura 2: Los cortes histológicos muestran una lesión monótona compuesta de proliferación de células de aspecto plasmocitoide entre trabéculas óseas; estas células son de citoplasma moderado y núcleo marginal granular con zona Golgi paranuclear. A) La población es positiva a CD138. B) Confirmación de estirpe de célula plasmática y monoclonalidad asociada con restricción de cadenas ligeras kappa (kappa+, lambda-). C y D) Confirmación del diagnóstico.

Figura 3:

Imágenes de resonancia magnética de control postoperatorio en cortes sagitales y axiales de columna torácica sin evidencia de tumor.
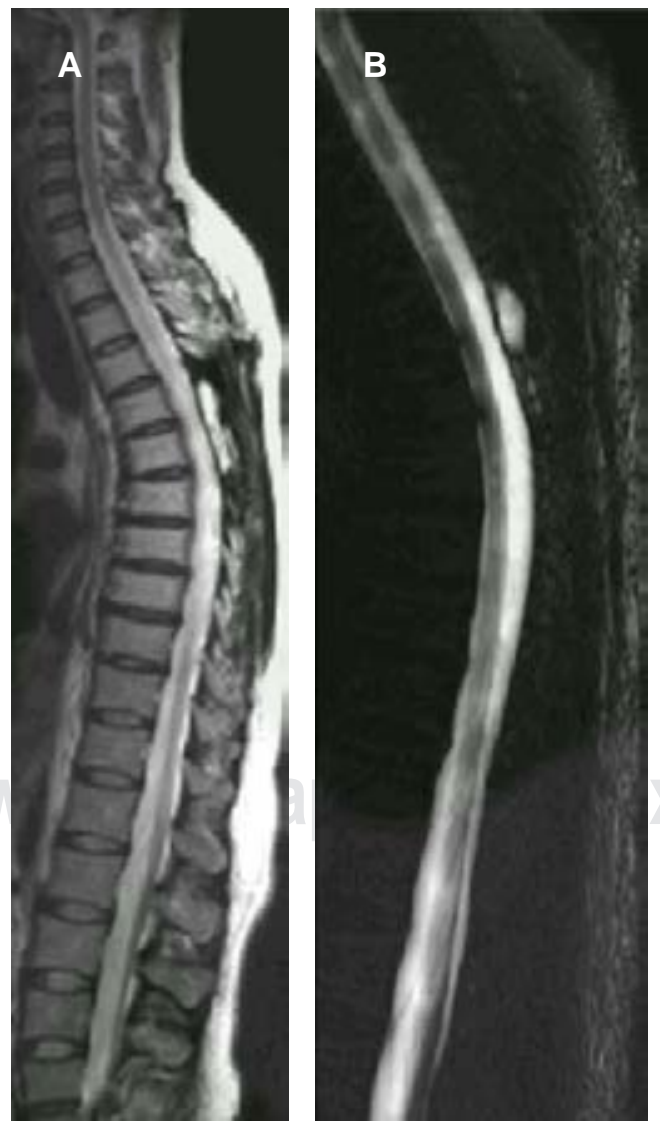
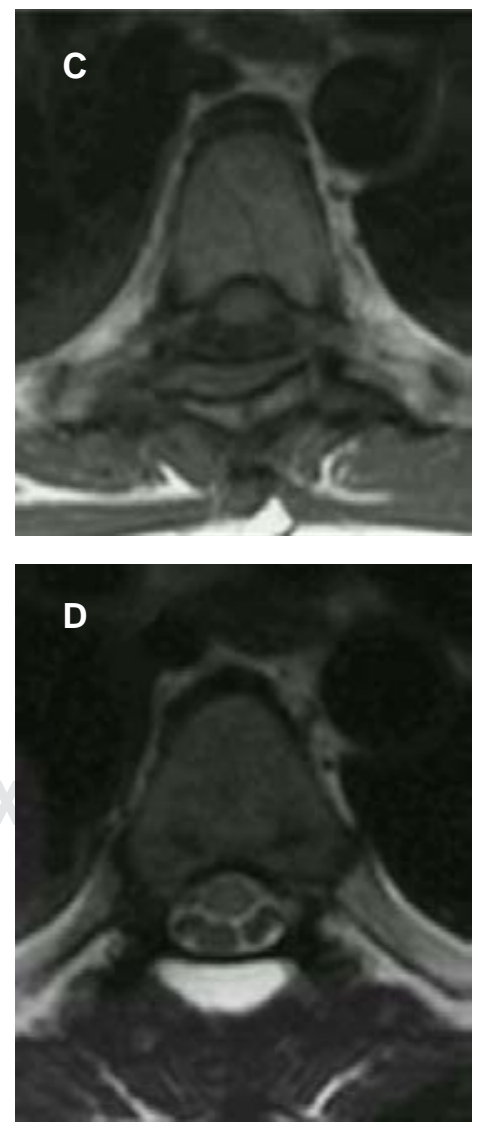
Se realizó una laminectomía de T4-T5, apreciando tumoración epidural de $4 \times 2 \mathrm{~cm}$ de consistencia blanda y vascularizada y sin infiltración a tejidos adyacentes; es fácilmente disecable y con duramadre integra. Se realizó una biopsia escisional con resultado histopatológico que confirma plasmocitoma solitario (Figura 2).

La paciente evolucionó satisfactoriamente con mejoría clínica y mejoría progresiva de la fuerza muscular y de la sensibilidad (Figura 3). Se inició manejo conjunto con los departamentos de Hematología, Oncología Médica y RadioOncología. A seis años de seguimiento la paciente se encuentra sin recidiva y libre de manifestaciones neurológicas.

El plasmocitoma solitario es una neoplasia caracterizada por proliferación monoclonal de células plasmáticas que no involucra desorden a nivel de médula ósea. Representa 5-10\% de las neoplasias de las células plasmáticas. ${ }^{1}$ La OMS lo clasifica en: plasmocitoma solitario de hueso y plasmocitoma solitario extramedular. Este último afecta las vías aéreas superiores hasta en $90 \%$ de los casos. ${ }^{2}$ La literatura anglosajona reporta sólo siete casos hasta el momento; nosotros documentamos el octavo caso a nivel mundial y el primero en América Latina.
El diagnóstico diferencial de este tipo de tumores incluye neoplasias primarias, neoplasias benignas y metástasis en el espacio epidural, siendo un reto diagnóstico y terapéutico, debido a su baja incidencia y localización. El plasmocitoma solitario es una causa inusual de mielopatía. ${ }^{3}$ El tratamiento incluye la escisión quirúrgica para el diagnóstico histológico y la limitación del daño neurológico, sin embargo, la terapia adyuvante sigue siendo el tratamiento de elección para este tipo de neoplasias. La cirugía descompresiva en etapas tempranas tiene resultados favorables sobre la función neurológica.

\section{REFERENCIAS}

1. Kilciksiz S, Karakoyun-Celik O, Agaoglu F, Haydaroglu A. A review for solitary plasmacytoma of bone and extramedullary plasmacytoma. Scientific World Journal. 2012; 2012: 895765.

2. Kumar A, Satyarthee G, Sable M, Suri V, Sharma B. Solitary extramedullary plasmacytoma of thoracic epidural space presenting with dorsal compressive myelopathy: a case report and review of literature. J Neurosci Rural Pract. 2015; 6: 410-412.

3. Lourbopoulos A, Ioannidis P, Balogiannis I, Stavrinou P et al. Cervical epidural plasmacytoma presenting as ascending paraparesis. Spine J. 2011; 11: e1-4. 